\title{
Structural and Electrochemical Properaties of a Tungsten Compound Film Precipitated from an Aqueous Solution ${ }^{* 1}$
}

\author{
Hiroaki TADA*, Kozo FUJlNo, Hideo KAWAHARA and Nobuyoshi BABA ${ }^{\dagger}$ \\ Received December 14, 1986 ; Accepted May 8, 1986

\begin{abstract}
Electrochromic tungsten compound films (precipitation films
) were prepared from an aqueous solution containing a polynuclear oxalatotungstate $(V)$ complex. The results of the infrared reflection spectra indicate that oxalate ligand is present in these films, coordinating to the tungsten atoms.

The electrochemical properaties of these films were investigated using cyclic voltammetry, and two redox waves were obseraved (anodic current peak; $-0.36,0.63 \mathrm{~V}$ ), whereas there was only one in a sputtered tungsten trioxide film(-0.3V). The redox wave at more positive potential in the precipitation film was ascribed to the cation injection/extraction into/from sites like crown ether formed by oxalato ligands.
\end{abstract}

\section{Introduction}

For the purpose of applying to electrochromic displays (ECDS), tungsten trioxide films prepared by various physical vapour deposition methods (PVD) have been vigorously investigated. These methods, however, are generally expensive and difficult in forming large area films.

Taking into these drawbacks in PVD method for obtaining electrochromic tungsten compound films precipitated from an aqueous solution containing an oxalatotungstate (V) complex. In this study, we investigate the structural and electrochemical properaties of these films together with a sputtered tungsten (VI) trioxide film.

The relationship between the structure and its electrochemical properaties is discussed.

\section{Experimental}

Guaranteed reagent grade chemicals were used throughout the experiments.
The precipitation films were prepared by the method of Baba et al. ${ }^{1)}$ The mixtures of $\mathrm{K}_{2} \mathrm{WO}_{4}$ aq. and $\mathrm{H}_{2} \mathrm{C}_{2} \mathrm{O}_{4}$ aq. with their concentrations of 0.062 and 0.12 mol. $\mathrm{dm}^{-3}$, respectively, were used as a catholyte, and saturated $\mathrm{H}_{2} \mathrm{C}_{2} \mathrm{O}_{4}$ aq. was used as an anolyte.

The oxalatotungstate(V) complex was synthesized by electrolytic reduction of the catholyte with a $\mathrm{Pb}$ cathode and a constant current density of $20.8 \mathrm{~mA} / \mathrm{m}^{2}$.

The duration of the electrolysis was 1.5 times longer than that estimated from Faraday's law. This solution was cooled to $15^{\circ} \mathrm{C}$ and the conductive glass substrates were immersed in the solution for 18 hours. A uniform blue coloured film consisting of a tungsten compound with film thickness of approximately $500 \mathrm{~nm}$ was obtained. Samples of tungsten (VI) trioxide films were prepared by rf sputtering in $10 \%$ oxygen and $90 \%$ argon gas at a pressure of $40 \mathrm{~mm}$ Torr.

Central Research Laboratory, Nippon Sheet Glass Co. Ltd. 2 Kaidoshita, Konoike Itami-city 664

+ Tokyo Metropolitan University, 2-1-1 Fukasawa, Setagaya-ku, Tokyo 158

* H.Tada et al. presented at the Annual Meeting of the Electrochem. Soc., Japan (Yokohama) 1985 
(5. $\left.33 \times 10^{3} \mathrm{~Pa}\right)$.

Cyclic voltammetry measurements were performed with a potentiostat (Hokuto Denko Model HA-301), combined with a function generator (the same company, Model HB-104). The counter electrode was a carbon rod, and an $\mathrm{Ag} / \mathrm{AgCl} / 0.1 \mathrm{~mol}$. $\mathrm{dm}^{-3} \mathrm{LiCl}$ was served as a reference electrode. The electrolytes were used in a non-aqueous system of propylene carbonate $(P C)-0.3 \mathrm{~mol} . \mathrm{dm}^{-3} \mathrm{LiClO}_{4}$.

3. Results and Discussion Figure 1 shows the $x$-ray diffraction patterns of the precipitation films annealed at various temperatures. In the range of the annealing temperature lower than $300^{\circ} \mathrm{C}$, there is a peak at $2 \theta=$ $20-22^{\circ}$, where $2 \theta$ is the scattering angle, which can be assigned to that of the transparent conductive film( $\left.\mathrm{SnO}_{2}\right)$ underlying the precipitation films.

While annealing temperature is higher than $400^{\circ} \mathrm{C}$, many peaks other than those of tin oxide appear. It is apparent from these finding that a precipitation film annealed at a temperature lower than $300^{\circ} \mathrm{C}$ is amorphous and that the temperature of crystallization of the precipitation film is between $300^{\circ} \mathrm{C}$ and $400^{\circ} \mathrm{C}$. Elemental

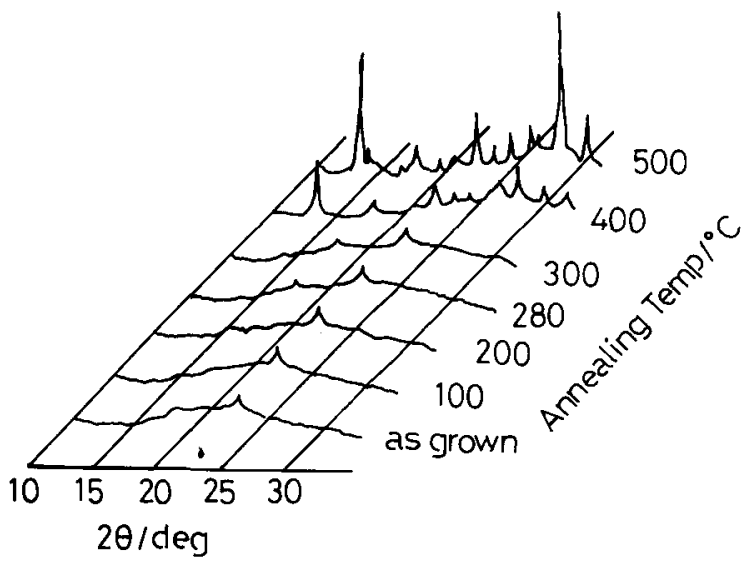

Fig.1. X-ray diffraction patterns of the precipitation films annealed at various temperatures. analysis of the precipitation film was carried out using an X-ray microanalyzer. Carbon and potassium were detected together with tungsten and oxygen.

Figure 2 shows the molar ratios of carbon and oxygen over tungsten as a function of annealing temperature,relative to those of the "as grown film". The result indicates that the ratio of oxygen to tungsten is almost independent of annealing temperature. on the other hand, the ratio of carbon to tungsten remarkably decreases in the range of annealing temperature higher than $200^{\circ} \mathrm{C}$. The infrared reflection spectra of films annealed at various temperatures were measured; the results are shown in Figure 3. This figure shows that the bands of the "as grown film" appear at $1720,1680,1400,960$ and $730 \mathrm{~cm}^{-1}$. Among them, the predominant bands at 1720 and $1680 \mathrm{~cm}^{-1}$ can be assigned to anti-symmetric $\mathrm{C}=\mathrm{O}$ stretching of oxalato ligand. According to Fujita et al. ${ }^{3)}$ the two anti-symmetric stretching modes of $\mathrm{C}=0$, which are $\mathrm{IR}=$ active, are present, if $\alpha$-diketone like oxalato ligand is fixed to the tungsten atom in the cis-form. Thus it is strongly suggested that oxalate group is coordinated to tungsten atom. Moreover, the intensities of the bands

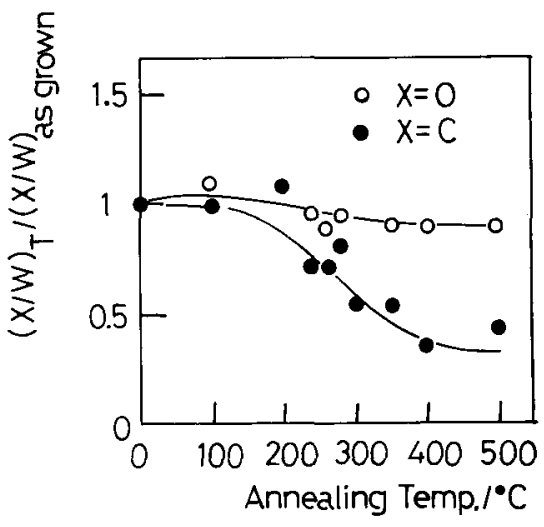

Fig.2. Molar ratios of carbon and oxygen over tungsten as a function of annealing temperature relative to those of the "as grown film". 
at 1720,1680 and $1400 \mathrm{~cm}^{-1}$ decreases as the annealing temperature increases, and decrement is pronounced over the range of annealing temperature above $200^{\circ} \mathrm{C}$. From this result and those by $\mathrm{X}=$ ray microanalyzer, it is thought that oxalato group coordinating to tungsten atom is removed from the films, which is converated to carbon dioxide by heating. According to the previous paper ${ }^{4)}$, other bands at 1400,960 and $730 \mathrm{~cm}^{-1}$ are assigned to $\mathrm{v}_{\mathrm{s}}(\mathrm{C}-\mathrm{O})$, $v_{\text {as }}(W=0)$ and $v_{s}(W-O-W)$, respectively.

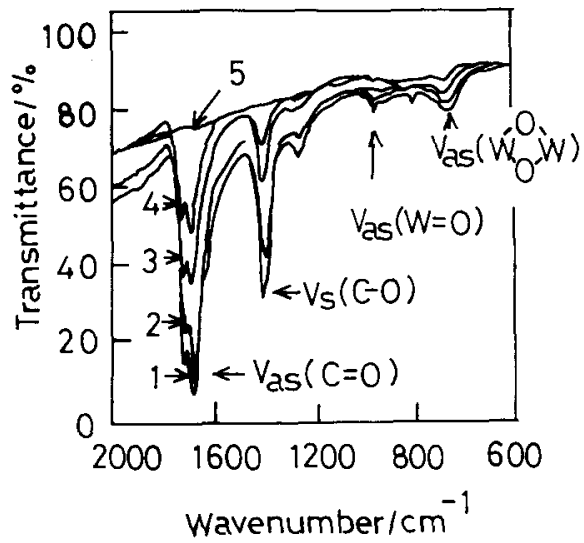

Fig.3. Infrared reflection spectra of the precipitation films annealed at various temperatures; 1 ; as grown, 2 . $100^{\circ} \mathrm{C}, 3 ; 200^{\circ} \mathrm{C}, 4 ; 300^{\circ} \mathrm{C}, 5 ; 350^{\circ} \mathrm{C}$.

The "as grown film" is blue. Now the origin of this colouration was studied. Figure 4 shows XPS spectra of the $\mathrm{w}_{4 \mathrm{f} 7 / 2,5 / 2}$ photoelectron lines of tungsten(VI) trioxide powder, the precipitation films, a sputtered tungsten trioxide film and a hydrogen tungsten bronze film. This hydrogen tungsten bronze film is obtained by electrochemical reduction of the sputtered film in a dilute acid solution. Peaks of the "as grown precipitation film" are very broad, becoming sharp along with an increase in annealing temperatures. In the spectrum of the film annealed at $280^{\circ} \mathrm{C}$, the peaks corresponding to $4 f 7 / 2$ and $5 / 2$ are observed at $36.0,38.0 \mathrm{ev}$, respectively; they are in good agreement with those of tungsten(VI) trioxide powder and the sputtered film. From this finding, it is evident that the tungsten in the $\mathrm{film}$ is present in the 6 -valent state $\left(w^{6+}\right)$.

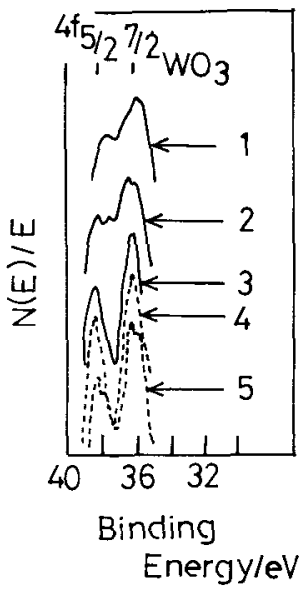

Fig.4. XPS spectra of the $W_{4 f 7 / 2,5 / 2}$ photoelectron lines for the temperatures and a sputtered tungsten trioxide film: l; as grown, $2 ; 100^{\circ} \mathrm{C}, 3$; $250^{\circ} \mathrm{C}$, sputtered films 4 ; tungsten trioxide film, 5 ; tungsten hydrogen bronze film.

For the "as grown film", shoulders are observed at energy levels from 0.3 to $0.6 \mathrm{eV}$ lower than those corresponding to $\mathrm{w}^{6+}$. These energy levels are in fairly good agreement with those of the shoulders that are ascribed to $\mathrm{w}^{5+}$ in the hydrogen tungsten bronze film. This indicates that the tungsten in the "as grown film" is present in the mixed valences of $\mathrm{w}^{6+}$ and $\mathrm{w}^{5+}$.

Figure 5 shows the electronic spectra of the precipitation films annealed at various temperatures. It is apparent that the "as grown film" has a broad absorption maximum at about $900 \mathrm{~nm}$, and its intensity decreases with an increase in the annealing temperature, becoming very small in the visible region at $280^{\circ} \mathrm{C}$.

Taking into account the result of the XPS spectra, this absorption is assigned to be that due to an intervalency transition between $\mathrm{w}^{5+}$ and $\left.w^{6+} .5,6,7\right)$ Namely, the tungsten in the "as grown film" is present in the mixed valence state of $\mathrm{w}^{5+}$ and $\mathrm{w}^{6+}$ having a strong absorption in the visible resion. The absorption intensity at $900 \mathrm{~nm}$ of this decreases with an increase in annealing temperature, probably because of the oxidation of $\mathrm{w}^{5+}$ to $\mathrm{w}^{6+}$ by air.

Furthermore, the absorption almost disappears for the film annealed at $280^{\circ} \mathrm{C}$, in which all tungsten atoms are 


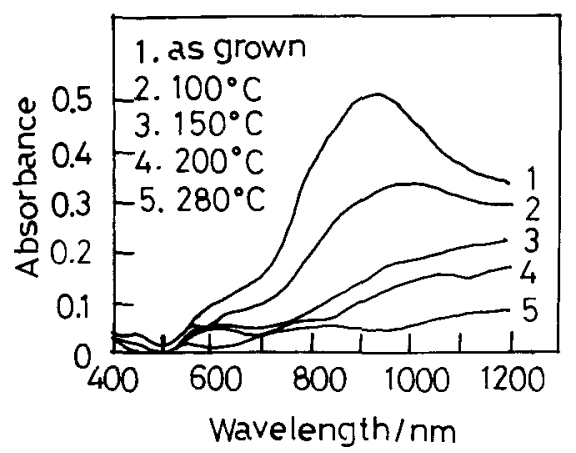

Fig.5. Electronic spectra of the precipitation films annealed at various temperatures.

oxidized to $\mathrm{w}^{6+}$.

Figure 6 shows the plots of optical density (OD) vs. charge passed (quantity of electricity), when a bleaching voltage is applied to a transparent conductive electrode with the "as grown films" ( 620 and $600 \mathrm{~nm}$ thick) in an electrolyte solution. Glassy carbon was used as a counter electrode. The plots are linear in both cases, and the slopes are almost the same.

This absorption is ascribed to an intervalency electron transfer between $\mathrm{w}^{5+}$ and $\mathrm{w}^{6+}$. Since one can assume for convenience that colour centers equal to the number of $\mathrm{w}^{5+}$ ions have been formed in the film, the quantity of the electricity, which is the intersection obtained by extraporating the straight lines to the abscissa, corresponds to the number of $\mathrm{w}^{5+}$ ions in the film. The ratio of the number of $\mathrm{w}^{5+}$ ions to that of all tungsten atoms in the film is estimated to be approximately 0.12 , by taking into account of the electricities, the film thickness, the density of tungsten $\left(6.39 \times 10^{21}\right.$ atoms $\left./ \mathrm{cm}^{3}\right)$ and areas of the films $\left(6.5 \mathrm{~cm}^{2}\right)$.

on the basis of the results described above, the structure of the "as grown film" can be supposed as shown in Figure 7. (A) is the structure of the oxalatotungstate (V) complex previously determined by Baba et a1. ${ }^{4)}$ It is suggested from the infrared reflection spectra that oxalato groups in the "as grown film" are coordinated to tungsten atom in such a manner that in the oxalatotungstate(V) complex. Moreover,

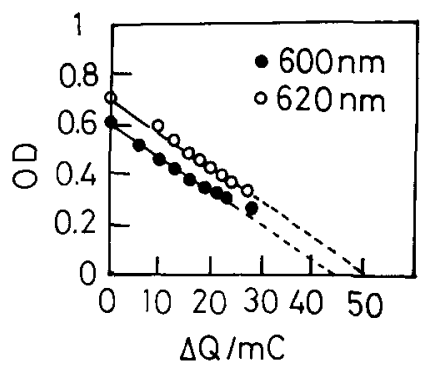

Fig.6. Plots of OD $(632.8 \mathrm{~nm})$ vs. electricity: counter electrode, glassy carbon, electrolyte, $0.3 \mathrm{~mol} . \mathrm{dm}$ RbSCN acetonitrile solution, applied voltage, 1. OV.

from the fact that the viscosity of the solution containing the oxalatotungstate (V) complex increased with time, the precipitation film consists of polymers of the unit (A) with various degrees of polymerization. Most of tungsten atoms in the "as grown film" are $\mathrm{w}^{6+}$, in contrast to the oxalatotungstate(v) complex, in which all the tungsten atoms are in the state of $\mathrm{w}^{5+}$.

In addition, the molar ratio of tungsten atoms to oxalato groups in the "as grown film" is greater than that in the oxalatotungstate(V) complex. Thus, during the film formation from the oxalatotungstate(V) complex solution, a part of oxalato groups is eliminated from the complex and a part of the $w^{5+}$ ions is simultaneously oxidized to $W^{6+}$. A proposed structure of the "as grown film"(B) indicates a wide space, surrounded by six oxygen atoms shown as

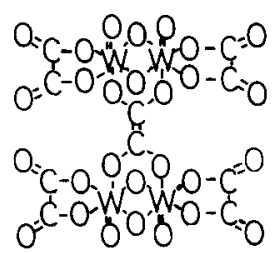

(A) Structure of tungstenoxalate

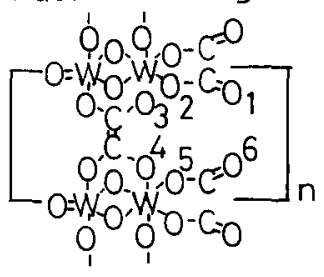

(B) Proposed structure of the film

Fig.7. Representation of the structures of oxalatotungstate (V) complex(A) and the "as grown precipitation film"(B). 
01-06 in Figure 7, which is like as dibenzo-18 -crown-6.

Figure 8 shows cyclic voltammograms of a tin(IV) oxide film, an amorphous sputtered tungsten(VI) trioxide film and the precipitation films.

In the tin oxide film, no redox reaction occured in the potential range between -1.0 and $1.0 \mathrm{~V}$ relative to the $\mathrm{Ag} / \mathrm{AgCl}$ reference electrode. In the sputtered tungsten(VI) trioxide film, the cathodic current appeared to flow at approximately $-0.17 \mathrm{~V}$; and the peak of the anodic current was at approximately $-0.3 \mathrm{~V}$. This film was blue during the potential more negative than approximately $-0.2 \mathrm{~V}$ and was colourless during the potential more positive than approximately -0.1V. Furthermore, this redox potential was comparable to that corresponding to the simultaneous double injection/ extraction of electrons and lithium ions into/from a evaporated tungsten(VI) trioxide film. ${ }^{8}$

From these results, it was thought that the electrochemical reaction corresponding to the redox waves in the sputtered tungsten(VI) trioxide film was represented by eq. (1)

$$
\mathrm{WO}_{3}+\mathrm{xLi}^{+}+\mathrm{xe}^{-}=\mathrm{Li}_{\mathrm{x}} \mathrm{WO}_{3}
$$

(blue)

Arnoldussen et al. ${ }^{9}$ ) reported that amorphous tungsten(VI) trioxide was composed of $\mathrm{w}_{3} \mathrm{O}_{9}$ trimers bonded together

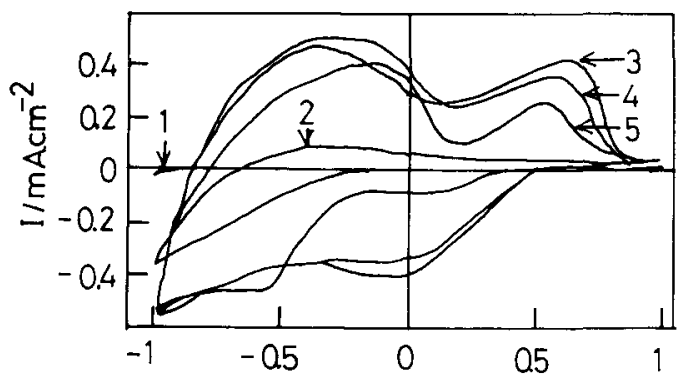

$\mathrm{E} / \mathrm{V}$ vs. $\mathrm{Ag}-\mathrm{AgCl}-0.1 \mathrm{NLIC}$

Fig. 8. Cyclic voltammograms of a tin oxide film ( $\left.\mathrm{SnO}_{2}\right)$, a sputtered tungsten trioxide films on $\mathrm{SnO}_{2}$ and the precipitation film on $\mathrm{SnO}_{2}: 1$; $\mathrm{SnO}_{2}, 2$; sputtered tungsten trioxide, 3 ; the "as grown film", 4; the precipitation film annealed at $100^{\circ} \mathrm{C}, 5$; the precipitation film annealed at $250^{\circ} \mathrm{C}$. by water-bridge, hydrogen, and van der Waal's bonding. Accordingly, lithium ions may be injected into the sites surrounded by $\mathrm{W}-\mathrm{O}$ and/or $\mathrm{W}=\mathrm{O}$ bonds.

It is of great interest here that there were two redox couples in the precipitation films. Namely, the first cathodic current began to flow at approximately $0.56 \mathrm{~V}$, reaching a maximum at $-0.1 \mathrm{~V}$ and the second cathodic current flew further. The peaks of anodic current corresponding to them were apparently observed at -0.36 and $0.63 \mathrm{~V}$.

When the potential was scanned from $-0.1 \mathrm{~V}$ to $1.0 \mathrm{~V}$, the precipitation film was deep blue during the potential more negative than $-0.36 \mathrm{~V}$, and was pale blue within the potential between $-0.36 \mathrm{~V}$ and $0.63 \mathrm{~V}$, and was colourless during the potential more positive than $0.63 \mathrm{~V}$.

Moreover, as the annealing temperature of the precipitation films increased, the magnitude of the first redox current decreased, whereas that of the second redox current hardly changed.

Taking into account such a colour change and the result of chemical analysis that lithium could not be detected from the film electrolyzed at the potential more positive than $0.63 \mathrm{~V}$, and was detectable from the film electrolyzed at the potential more negative than $0.5 \mathrm{~V}$, the electrochemical reaction corresponding to the redox waves in the precipitation film was ascribable to the double injection/extraction of electrons and lithium ions as represented by eq. (1).

Moreover, the fact that two couples of redox waves were observed in the precipitation film could be explained by assuming the existance of two kinds of cation injection sites on the basis of the structure of the precipitation film as follows: One is the sites surrounded by $W-O$ or $W=O$ bonds of the precipitation $f i l m$, the redox wave at more negative potential was thought to correspond to the cation injection/extraction into/from these sites. Because this redox potential was comparable to that of the sputtered and evaporated tungsten(VI) trioxide films.

Another is the characteristic sites 
in the precipitation film surrounded by oxalato ligands, the cation injection/ extraction into/from these sites was thought to correspond to the more positive redox wave characteristic of the precipitation film.

Green et a $1 .^{10)}$ reported that the only terms of importance in the binding energy of sodium in tungsten(VI) trioxide would be the local interaction energy of the sodium ion with the tungsten(VI) trioxide lattice and the average kinetic energy of the free electrons, since tungsten(VI) trioxide has a large static dielectric constant.

Accordingly, if lithium ions and electrons injected into the precipitation film would dissociate, lithium ions at the sites surrounded by the oxalato Iigands were thought to be stabilized by ion-dipole interaction like as a lithium ion-crown ether complex. This explains that the redox reaction, which is thought to correspond to the cation injection/extraction into/from the sites like crown ether, occured at more positive potential. Moreover, the result that the current decreases with the heating temperature of the film can be also explained in terms of the fact that oxalato ligands are eliminated with heating and the numbers of the sites like crown ether decrease.

These results can be interpreted in terms of relating them to the structure of the precipitation films as described above. That is, there are two kinds of sites, into which cations can be injected. In the first cases, a cation is injected into a site, which is surrounded by the coordinated oxalato groups. The cation injection into this site is thought to be energetically easy and the stabilization energy of this cation be greater, since this structure is like crown ether. This process is corresponding to the first redox reaction, and the second one is thought to be corresponding to the cation injection into the W-O-W interstitial sites, because the redox potential is almost equal to that of the sputtered tungsten(VI) trioxide film.

\section{References}

1) N.Baba and T.Yoshino; J.Appl.Electrochem., $12,607(1982)$

2) H.Kaneko, K.Miyake and Y.Teramoto; J. Appl.Phys. ,53,4416 (1982)

3) J.Fujita, K.Nakamoto and M.Kobayashi;J. Phys.Chem . 61, 1014(1957)

4) N.Baba, T.Yoshino and K.Schwochau; Memoirs Fac. Techn.Tokyo Metropol.Univ. 32, 3207 (1982)

5) B.W.Faughnan, R.S.Crandall and P.M.Heyman; RCA Rev., 36,117(1975)

6) O.F.Schirmer and E.Salge; J.Phys.C,13, L1067(1980)

7) O.F.Schirmer, V.Wittwer, G.Bauer and G. Brandt; J.Electrochem.Soc., 124,749 (1977)

8) O.Bohnke, C.Bohnke and G.Robert; Solid State Ionics, 6,121 (1982)

9) T.C.Arnoldussen; J.Electrochem.Soc., 128, no. 1, 117 (1981)

10)M.Green and K.S.Kang; Thin Solid Films; $\underline{62}, 385$ (1979) 